Revista Ambientale

Revista da Universidade Estadual de Alagoas/UNEAL e-ISSN 2318-454X, Ano 13, Vol. 13 (4), 2021 https://doi.org/10.48180/ambientale.v13i4.318

\title{
Métodos de controle de formigas cortadeiras em sistemas orgânicos de produção: uma revisão
}

\section{Leaf-cutting ant control methods in organic production systems: a review}

\author{
Joabe Rodrigues Pereira ${ }^{1}$ \\ Universidade Federal Rural do Rio de Janeiro \\ E-mail: joabeglobo@gmail.com
}

\begin{abstract}
Resumo - O controle de formigas cortadeiras é um dos grandes desafios da agricultura orgânica, onde são proibidos insumos químicos ou materiais transgênicos. Buscar métodos de controle de formigas cortadeiras (Hymenoptera: Formicidae) em sistemas orgânicos de produção. Foi realizado um levantamento em dezembro de 2020, nas das bases de dados Periódicos CAPES e Google acadêmico. Foram encontrados 11 artigos, que através da sua metodologia e resultados poderiam ser aplicados para o controle de formigas cortadeiras em cultivos orgânicos, através de métodos biológicos, mecânicos, iscas biológicas, produtos naturas e plantas repelentes. Existem alternativas para o controle de formigas cortadeiras em sistemas orgânicos de produção que são: controle mecânico, controle biológico, plantas atraentes ou repelentes, mas é preciso a realização de mais estudos e a disponibilidade desses produtos no mercado.
\end{abstract}

Palavras-chave: Mimercofauna; Atta spp.; Acromyrmex spp.; Manejo orgânico.

\begin{abstract}
The control of leaf-cutting ants is one of the great challenges of organic agriculture, where chemical inputs or transgenic materials are prohibited. To seek methods of controlling leaf-cutting ants (Hymenoptera: Formicidae) in organic production systems. A survey was conducted in December 2020, in the CAPES and Google Academic Journal databases. Eleven articles were found, which through their methodology and results could be applied to the control of leaf-cutting ants in organic crops, through biological and mechanical methods, biological baits, natural products and repellent plants. There are alternatives for the control of leaf-cutting ants in organic production systems that are: mechanical control, biological control, attractive or repellent plants, but more studies and the availability of these products on the market are needed.
\end{abstract}

Keyword: Mimercofauna; Atta spp.; Acromyrmex spp.; Organic management 


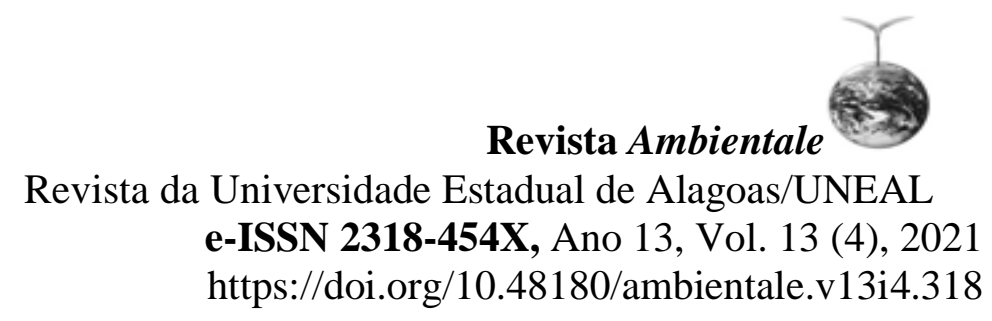

\section{Introdução}

Entre os grupos de insetos terrestre que apresentam elevada abundância, estão as formigas (ESTRADA et al., 2019; MARCHIORI, 2020). A família Formicidae é composta pelas formigas que, juntamente com as abelhas e vespas pertencem à ordem Hymenoptera (WARD, 2010).

As formigas são insetos eusociais expressivamente comuns, abundantes e com elevada diversidade taxonômica e comportamental, em relação ao hábito alimentar e de nidificação, pois podem habitat o solo serapilheira ou as plantas e existem espécies predadoras, aquelas que consumem frutos e sementes, ocorrem espécies fungívoras e detritívoras e ainda as que se alimentam de líquidos açucarados exsudados por plantas e hemípteros (HÖLLDOBLER \& WILSON, 1990; BACCARO et al., 2015).

Entre os gêneros de formigas mais conhecido nas Américas, estão as formigas cortadeiras dos gêneros Atta e Acromyrmex (MULLER et al., 2017). No Brasil são conhecidas como "Saúvas', 'Quenquéns", 'Xenxéns" (DELLA LUCIA et al., 2011).

A saber, relatos afirmam que as formigas cortadeiras são conhecidas desde a época do descobrimento do Brasil (DELLA LUCIA, 2011). Esses gêneros estão presentes em vários ambientes, incluindo ecossistemas naturais, áreas cultivadas e pastagens (NADAI et al., 2012; CORASSA et al., 2015). Causando elevados prejuízos atacando inúmeras espécies agrícolas (DELLA LUCIA, 2011, LAZZARI et al., 2019; GIESEL et al., 2020).

Desse modo, as formigas cortadeiras ocorrem durante todo e atacam as plantas em todas as idades, por isso é preciso um controle integrado de práticas que vise garantir a produtividade das culturas (DELLA LÚCIA, 2000; MARINHO et al. 2006).

No cultivo orgânico um dos grandes desafios da atualidade é o controle de formigas cortadeiras, onde não são permitidos o uso de insumos químicos ou sintéticos ou transgênicos (NASCIMENTO et al., 2018).

Entre as formas de controle disponíveis para a agricultura orgânica é a utilização de substâncias naturais que são capazes de repelir essas pragas e ao mesmo tempo preservado a biodiversidade (SILVEIRA et al., 2020).

As formigas cortadeiras são consideradas uma das principais pragas dos setores agrícolas e florestais no Brasil, trazendo prejuízos para a produtividade, podendo por exemplo em uma noite causar inúmeras perdas em áreas cultivadas (OLIVEIRA et al., 2001).

Segundo Della Lúcia (2011), apenas as formigas cortadeiras podem ser responsáveis por perdas na produtividade em aproximadamente $12 \%$ a $17 \%$, em eucaliptais essa perda pode chegar a $60 \%$ e se não forem combatidas pode chegar até matar as árvores (LEMES \& ZANÚNCIO, 2019).

Desse modo, para que exista um controle eficiente no combate as formigas cortadeiras na agricultura orgânica, é preciso que se utilize de diversos métodos em conjunto, como o biológico, mecânico e cultural. Sempre utilizando de técnicas aplicáveis e disponíveis para que possa ser viável desde ao pequeno a médio produtor orgânico.

Contudo, é preciso que sempre realize o monitoramento prévio nos cultivos orgânicos para que não se estabeleça de maneira incontrolável essa praga, realizando o controle antes da implantação da cultura.

O controle de formigas cortadeiras é um dos grandes gargalos da agricultura orgânica, onde são proibidos insumos químicos ou materiais transgênicos. 
Revista Ambientale

Revista da Universidade Estadual de Alagoas/UNEAL e-ISSN 2318-454X, Ano 13, Vol. 13 (4), 2021 https://doi.org/10.48180/ambientale.v13i4.318

Por isso, objetivo desse trabalho foi trazer alternativas descritas na literatura nos últimos cinco anos, para o controle de formigas cortadeiras em sistemas orgânicos de produção, para que o produtor possa combater essa praga de maneira sustentável e preservando o ambiente.

\section{Materiais e métodos}

Foi feito um levantamento da literatura em dezembro de 2020, nas bases de dados Periódicos CAPES e Google Acadêmico. Os descritores utilizados foram os seguintes: "Formicinae" AND "Atta sp" AND "Acromyrmex sp" AND "Organic management" em todas as bases de dados. Foram selecionados 11 artigos sendo incluídos segundo os critérios de elegibilidade conforme a Figura 1. Os critérios de inclusão foram: artigos nos idiomas inglês, espanhol e português, nos últimos cinco anos, envolvendo todos os métodos de controle e manejo de formigas cortadeiras que são permitidos ou novos que podem ser incluídos nos sistemas orgânicos de produção. Os critérios de exclusão foram artigos de revisão de literatura.

FIGURA 1. Fluxograma e critérios de seleção e inclusão dos artigos.

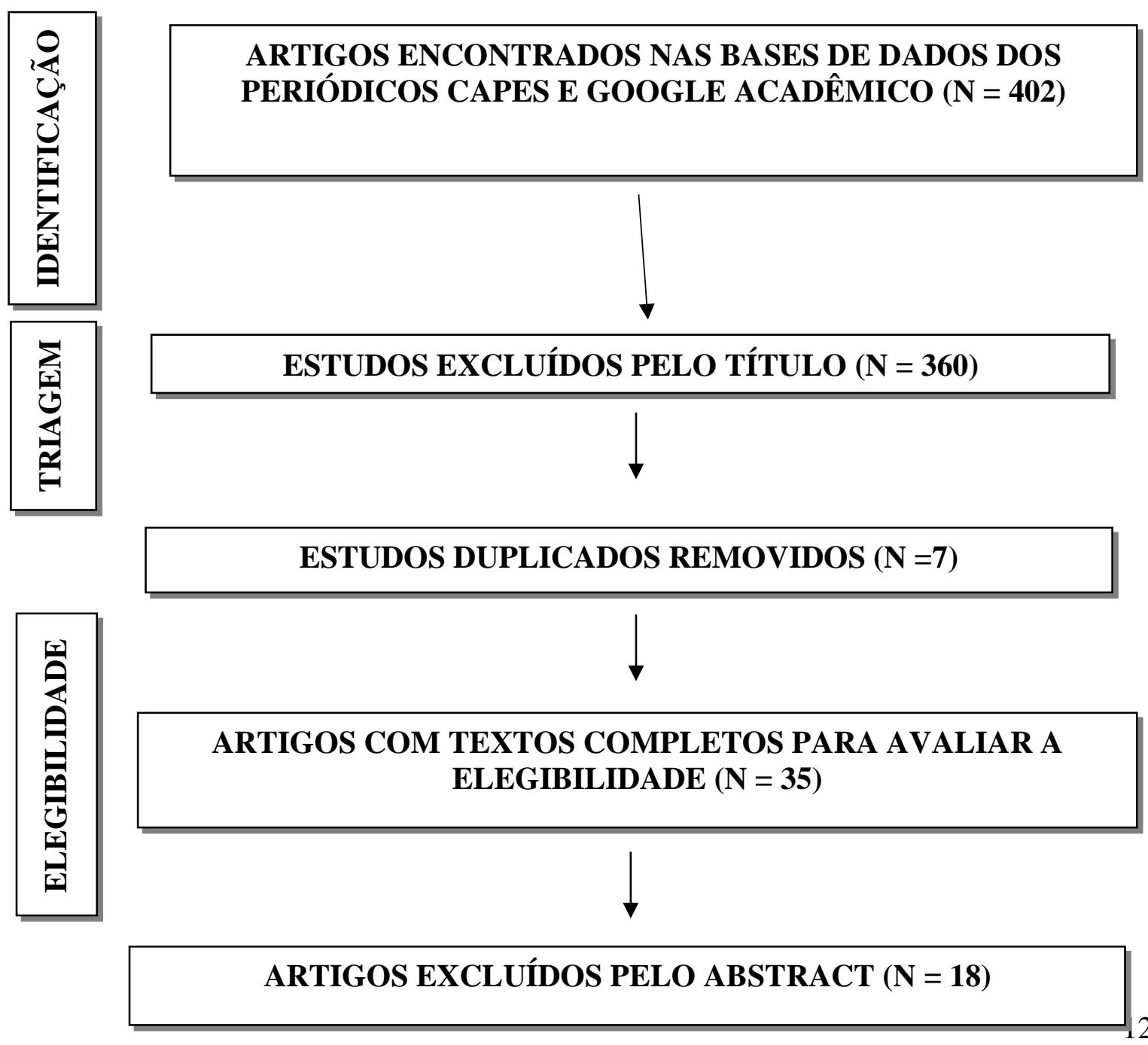


Revista da Universidade Estadual de Alagoas/UNEAL e-ISSN 2318-454X, Ano 13, Vol. 13 (4), 2021

https://doi.org/10.48180/ambientale.v13i4.318

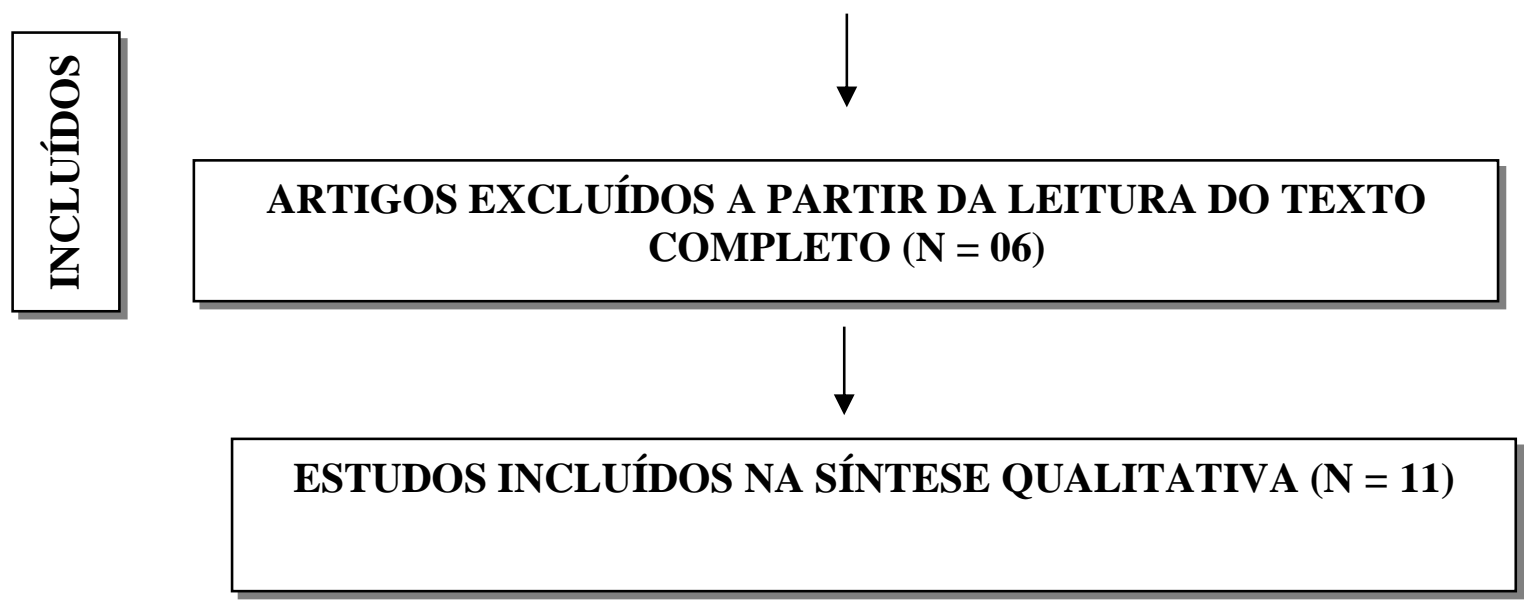

Resultados e discussão

Os resultados do presente estudo encontram-se na Tabela 1. 
Revista Ambientale

Revista da Universidade Estadual de Alagoas/UNEAL

e-ISSN 2318-454X, Ano 13, Vol. 13 (4), 2021

https://doi.org/10.48180/ambientale.v13i4.318

Tabela 1 - Demonstrativo dos artigos que integram a Revisão Integrativa

\begin{tabular}{|c|c|c|c|c|c|c|}
\hline$\# \mathbf{N}$ & Data & Título & Autores & Periódico & Objetivos & Resultados \\
\hline 1 & 2016 & $\begin{array}{l}\text { Toxicity of plant } \\
\text { extracts from Bahia, } \\
\text { Brazil, to Atta sexdens } \\
\text { sexdens } \\
\text { (Hymenoptera: } \\
\text { Formicidae) workers }\end{array}$ & $\begin{array}{l}\text { Gomes, M. D. C. } \\
\text { A. R.; de Paula, V. } \\
\text { F.; Moreira, A. A.; } \\
\text { Castellani, M. A.; } \\
\text { de Macedo, G. E. } \\
\text { L. }\end{array}$ & Sociobiology & $\begin{array}{l}\text { Avaliar a toxicidade das espécies vegetais } \\
\text { por partes da planta, folha e casca: } \\
\text { Aspidosperma spruceanum Benth ex. Mull } \\
\text { Arg., Casearia sylvestris Sw. e Esenbeckia } \\
\text { grandiflora Mart. Na folha e ramo: } \\
\text { Casearia arborea (Rich.) Urb., } \\
\text { Erythroxylum affine A.St.-Hil., } \\
\text { Zanthoxylum rhoifolium Lam. Em casas e } \\
\text { galhos: Ocotea brasiliensis Coe-Teix,. Na } \\
\text { folha, casca e ramo: Tabernaemontana } \\
\text { bracteolaris Mart. ex Müll.Arg. Para } \\
\text { controle de operárias de Atta sexdens } \\
\text { sexdens L. (Hymenoptera Formicidae). }\end{array}$ & $\begin{array}{l}\text { Por meio de contato os extratos de folhas e ramos de } Z \text {. rhoifolium e } \\
\text { da casca de } S \text {. amara foram os mais tóxicos. Entretanto, por ingestão, } \\
\text { quatro extratos foram tóxicos e mostraram ação retardada. O extrato } \\
\text { de ramos de Z. rhoifolium apresentaram a ação mais lenta ( } \$ 50=10 \\
\text { dias). Característica essa que é crucial para iscas tóxicas. Os extratos } \\
\text { de folhas e ramos de } Z \text {. rhoifolium foram os únicos com contato e } \\
\text { ingestão com toxicidade para operárias de } A \text {. sexdens sexdens. }\end{array}$ \\
\hline 2 & 2016 & $\begin{array}{l}\text { Uso de extratos } \\
\text { feromonais e de } \\
\text { farinha de gergelim em } \\
\text { iscas destinadas ao } \\
\text { controle de formigas- } \\
\text { cortadeiras }\end{array}$ & $\begin{array}{l}\text { Gabriela } \\
\text { Domingos de } \\
\text { Figueiredo } \\
\text { Tatagiba Araujo. }\end{array}$ & $\begin{array}{l}\text { Tese (Doutorado em Produção } \\
\text { Vegetal) - Universidade } \\
\text { Estadual do Norte Fluminense } \\
\text { Darcy Ribeiro. Centro de } \\
\text { Ciências e Tecnologias } \\
\text { Agropecuárias. Laboratório de } \\
\text { Entomologia e Fitopatologia. } \\
\text { Campos dos Goytacazes, RJ. }\end{array}$ & $\begin{array}{l}\text { Verificar se o crescimento do fungo } \\
\text { simbionte de A. laevigata através de iscas } \\
\text { formuladas com farinha de semente de } \\
\text { folhas de gergelim seria inibido. }\end{array}$ & $\begin{array}{l}\text { A } 75 \% \text { a formulação de folhas de gergelim apresentarm ininterrupta } \\
\text { inibição e perda constante de massa de fungo. Através de iscas } \\
\text { formulaadas com farinha de gergelim demonstram potencial de } \\
\text { utilização no manejo alternativo de formigas-cortadeiras. }\end{array}$ \\
\hline 3 & 2017 & $\begin{array}{l}\text { Diversidade química, } \\
\text { genética e estudo do } \\
\text { potencial formicida de } \\
\text { óleos essenciais de } \\
\text { Eplingiella fruticosa } \\
\text { (Salzm.Ex Benth) } \\
\text { Harley \& } \text { J.F.B. } \\
\text { Pastore }\end{array}$ & $\begin{array}{l}\text { Dennis Crystian } \\
\text { Silva. }\end{array}$ & $\begin{array}{l}\text { Tese (doutorado em Agricultura } \\
\text { e Biodiversidade) } \quad- \\
\text { Universidade Federal de } \\
\text { Sergipe. }\end{array}$ & $\begin{array}{l}\text { Avaliar o potencial formicida do óleo } \\
\text { essencial de plantas nativas de E. fruticosa } \\
\text { do Estado de Sergipe. E realizar a } \\
\text { caracterização química e genética. }\end{array}$ & $\begin{array}{l}\text { Os óleos essenciais de quatro genótipos de E. fruticosa mostraram-se } \\
\text { tóxicos a operárias de Acromyrmex balzani e foram necessários } 4,54- \\
6,78 \mu \mathrm{L} \text {.L-1 de óleo para causar } 50 \% \text { de mortalidade nas formigas. } \\
\text { Quando aplicados isoladamente, cânfora e } 1,8 \text {-cineol foram mais } \\
\text { potentes que os óleos essenciais, enquanto } \beta \text {-cariofileno e óxido de } \\
\text { cariofileno foram menos tóxicos. Os tratamentos reduziram a } \\
\text { sobrevivência de A. balzani ao longo do tempo de exposição. O } \\
\text { comportamento de caminhamento das formigas foi alterado em função } \\
\text { da aplicação dos tratamentos e verificou-se que os óleos essenciais } \\
\text { testados são repelentes. }\end{array}$ \\
\hline 4 & 2017 & $\begin{array}{l}\text { Essential Oil of } \\
\text { Aristolochia trilobata: } \\
\text { Synthesis, Routes of }\end{array}$ & $\begin{array}{l}\text { Bruna Maria S. de } \\
\text { Oliveira; Carlisson } \\
\text { R. Melo; Péricles }\end{array}$ & Molecules & $\begin{array}{l}\text { Avaliar a atividade inseticida do óleo } \\
\text { essencial de Aristolochia trilobata e seus }\end{array}$ & $\begin{array}{l}\text { Quando aplicado por fumaginação o óleo essencial de } A \text {. trilobata e } \\
\text { seus componentes individuais principais foram eficiente contra as } \\
\text { operarias de A. balzani e A. sexdens. Esses componentes mostraram }\end{array}$ \\
\hline
\end{tabular}


Revista Ambientale

Revista da Universidade Estadual de Alagoas/UNEAL

e-ISSN 2318-454X, Ano 13, Vol. 13 (4), 2021

https://doi.org/10.48180/ambientale.v13i4.318

\begin{tabular}{|c|c|c|c|c|}
\hline$\# \mathbf{N}$ & Data & Título & Autores & Periódico \\
\hline & & $\begin{array}{l}\text { Exposure, Acute } \\
\text { Toxicity, Binary } \\
\text { Mixturesand } \\
\text { Behavioral Effects on } \\
\text { Leaf-Cutting Ants }\end{array}$ & $\begin{array}{l}\text { B. Alves; Abraão } \\
\text { A. Santos; Ane } \\
\text { Caroline ris. } \\
\text { Santos; Alisson da } \\
\text { S. Santana; Ana } \\
\text { Paula A. Araújo; } \\
\text { Pedro E. S. S. } \\
\text { Nascimento; Arie } \\
\text { F. Blank; Leandro } \\
\text { Bacci. }\end{array}$ & \\
\hline 5 & 2017 & $\begin{array}{l}\text { Plant-based } \\
\text { compounds with } \\
\text { potential as push-pull } \\
\text { stimuli to manage } \\
\text { behavior of leaf- } \\
\text { cutting ants }\end{array}$ & $\begin{array}{l}\text { Daiana Perri; } \\
\text { Norma Gorosito; } \\
\text { Patricia } \\
\text { Fernandez; } \\
\text { Micaela Buteler. }\end{array}$ & $\begin{array}{l}\text { Entomologia Experimentalis et } \\
\text { Applicata }\end{array}$ \\
\hline 6 & 2019 & $\begin{array}{l}\text { Actividad forrajera de } \\
\text { Acromyrmex striatus } \\
\text { (Roger,1863) } \\
\text { (Formicidae: Attini) en } \\
\text { un viñedo orgânico en } \\
\text { Mendoza, Argentina }\end{array}$ & $\begin{array}{l}\text { Dagatti, C. V.; } \\
\text { Bernabé, A. L.; } \\
\text { Rossi, L.; Becerra, } \\
\text { V.C. }\end{array}$ & Ediciones INTA \\
\hline 7 & 2019 & $\begin{array}{l}\text { Bacterial extracts for } \\
\text { the control of Atta } \\
\text { cephalotes } \\
\text { (Hymenoptera: } \\
\text { Formicidae) and its } \\
\text { symbiotic fungus } \\
\text { Leucoagaricus } \\
\text { gongylophorus } \\
\text { (Agaricales: } \\
\text { Agaricaceae) }\end{array}$ & $\begin{array}{lr}\text { Miguel Uribe } \\
\text { Londoño; Magally } \\
\text { Romero-Tabarez; } \\
\text { Adriana Ortiz- } \\
\text { Reyes. }\end{array}$ & Revista de Biología Tropical \\
\hline
\end{tabular}

Avaliar compostos à base de plantas em ensaios de laboratório com Acromyrmex ambiguus Emery (Hymenoptera:
Formicidae) por seu uso potencial como Formicidae) por seu uso potencial como repelente e estímulos atrativos para seien
usados em uma estratégia push-pull.

Descrever a composição da dieta de Acromyrmex striatus, para conhecer as preferências da alimentação de acordo com $\mathrm{o}$ fornecimento de plantas presentes e conseguir uma contribuição para o manejo da praga no cultivo da videira.

Avaliar as propriedades inseticidas e Dezessete extratos mostraram atividade inseticida de contato, 13 por antifúngicas efeito de extratos bacterianos ingestão, enquanto 8 apresentaram atividade antifúngica em formigas A. cephalotes e no fungo $L$. estatisticamente significativa. No total, 23 extratos bacterianos gongylophorus.
A polpa e a casa da laranja foram avaliadas e comparados como atrativos. Os resultados de bioensaios de laboratório indicaram que o arnesol é repelente em doses de $50 \mathrm{mg}$ e age sobre contato ou a uma distância muito curta. A polpa de laranja era mais atraente do que a casca, e compostos voláteis foram altamente responsáveis pela tração. Quando ambos os estímulos foram testados simultaneamente em um experimento de laboratório, a repelência do farnesol foi umentada na presença do odor da polpa da laranja. Quando testado em um experimento push-pull em campo, os resultados também mostraram um bom efeito repelente do farnesol bem como efeito atrativo da polpa de laranja.

Os resultados indicaram que A striatus coletou mais fragmentos de olhas nos meses de verão. As plantas monocotiledôneas predominaram e elas preferiram o material de plantas verdes em todas as estações estudadas. O uso de adubo verde nas entrelinhas pode ser m recurso para o manejo de A. striatus na vinha, desde que estas as espécies de plantas não competem com a cultura.

exibiram algum tipo de atividade para controlar Atta cefalotes. 
Revista Ambientale

Revista da Universidade Estadual de Alagoas/UNEAL

e-ISSN 2318-454X, Ano 13, Vol. 13 (4), 2021

https://doi.org/10.48180/ambientale.v13i4.318

$\begin{array}{lllll}\text { \#N } & \text { Data } & \text { Título } & \text { Autores } & \text { Periódico }\end{array}$
Biocida Natural para Cortadeiras $\begin{array}{lr}\text { Everton } & \text { Lazzari; } \\ \text { João } & \text { Victor }\end{array}$

Miranda

Inácio Neiva de

Carvalho; Airton

Rodrigues Pinto

Junior.

Novel Micaela Butelera, repellent for leaf- Andrea Marina cutting ants: tea tree oil Alma María Laura and its potential use as $\begin{array}{ll}\text { a management tool } & \text { Gorosito; Patricia } \\ & \text { Carina Fernández. }\end{array}$ International
Brazilian Journal of Technology

Desenvolver um produto natural, com ação biocida, através do composto do óleo extraílo da ca extriflo da casca da laranja para o controle Acromyrmex, na cultura do eucalipto.
O biocida produzido através da extração do óleo essencial da casca da laranja, mostrou potencial para o controle de formigas cortadeiras na cultura do eucalipto. de

Infestações

formigas cortadeiras

(Hymenoptera:

Formicidae) em plantio

de ermicidae) em plantio

$10 \quad 2019$

de eucalipto com

de sub-bosque na

região de Campos

região de Campos

Paraná
Tamires Louise Santos Lima.
Monografia (Graduação em Engenharia Florestal) Instituto de Floresta, Universidade Federal Rural do Rio de Janeiro.
Identificar o efeito da Melaleuc alternifólia (Myrtaceae) sobre formigas Acromyrmex spp. em laboratório e em campo.

Avaliar a infestação de formig cortadeiras nas áreas de cultivo de eucalipto da empresa Klabin S.A. relacionando co a densidade do sub-bosque presentes nessas areas.
Em laboratório, o efeito repelente da Melaleuca alternifólia foi perdido após quatro dias e seu efeito sobre o comportamento das formigas era evidente apenas em distâncias muito curtas. No campo, as formigas evitavam andar em papéis de filtro tratados com $M$. alternifólia a $1 \%$ colocado em as trilhas de forrageamento e os recursos alimentares cercados por $M$. alternifólia a $1 \%$ não foram coletados. M. alternifólia é um potente repelente de formigas cortadeiras de curto prazo e fontes de alimento atraentes podem ser protegidos do ataque de formigas cortadeiras por este óleo.

A manutenção do sub-bosque no cultivo do eucalipto deve ser considerada para auxiliar no controle de formigas cortadeiras. Do total de 398 talhões, não detectou a presença de formigueiro em $80 \%$, entretanto os outros 20\% apresentaram formigueiros de Atta spp. Ou Acromyrmex spp. Contudo, um número superior de formigueiros foi encontrados em áreas onde a densidade do sub-bosque foi considerada baixa. 
Revista Ambientale

Revista da Universidade Estadual de Alagoas/UNEAL e-ISSN 2318-454X, Ano 13, Vol. 13 (4), 2021

https://doi.org/10.48180/ambientale.v13i4.318

\begin{tabular}{|c|c|c|c|c|c|c|c|}
\hline$\# \mathbf{N}$ & Data & Título & Autores & & eriódico & Objetivos & Resultados \\
\hline 11 & 2020 & $\begin{array}{l}\text { Description using } \\
\text { ultramorphological } \\
\text { techniques of the } \\
\text { infection of Beauveria } \\
\text { bassiana (Bals.-Criv.) } \\
\text { Vuill. in larvae and } \\
\text { adults of Atta sexdens } \\
\text { (Linnaeus, 1758) } \\
\text { (Hymenoptera: } \\
\text { Formicidae) }\end{array}$ & $\begin{array}{lr}\text { Raphael } & \text { Vacchi } \\
\text { Travaglini; } & \text { Luiz } \\
\text { Carlos } & \text { Forti; } \\
\text { Andre } & \text { Arnosti; } \\
\text { Luis } & \text { Eduardo } \\
\text { Pontes } & \text { Stefanelli; } \\
\text { Allan Roberto } & \text { Fernandes } \\
\text { Ferreira; Roberto } \\
\text { da Silva } & \text { Camargo; } \\
\text { Maria Izabel } \\
\text { Camargo-Mathias. }\end{array}$ & $\begin{array}{l}\text { Boletim do } \\
\text { Emílio } \\
\text { Naturais }\end{array}$ & $\begin{array}{r}\text { Museu Paraense } \\
\text { Goeldi-Ciências }\end{array}$ & $\begin{array}{l}\text { Demonstrar por meio técnicas histológicas, } \\
\text { documentando em fotos o desenvolvimento } \\
\text { de B. bassiana na superfície do tegumento } \\
\text { do inseto larvas (imaturas) e operárias } \\
\text { (adultos) de A. sexdens para mostrar a } \\
\text { penetração das hifas do fungo, e como a } \\
\text { organização estrutural e a morfofisiologia } \\
\text { de o tegumento seria afetado. }\end{array}$ & $\begin{array}{l}\text { O controle biológico de A. sexdens que usam o fungo } B \text {. bassiana } \\
\text { devem focar a larvas, quando o ciclo biológico do tegumento ainda } \\
\text { está frágil (menos esclerotizado), permitindo adesão bem-sucedida e } \\
\text { germinação do fungo. A eliminação via contaminação imatura } \\
\text { interferiria diretamente na geração de novos indivíduos, afetando o } \\
\text { desenvolvimento de a colônia e, como consequência o sucesso da } \\
\text { espécie. }\end{array}$ \\
\hline
\end{tabular}




\section{Revista Ambientale \\ Revista da Universidade Estadual de Alagoas/UNEAL e-ISSN 2318-454X, Ano 13, Vol. 13 (4), 2021 https://doi.org/10.48180/ambientale.v13i4.318}

O objetivo do presente estudo foi o levantamento de métodos permitidos de manejo para o controle de formigas cortadeiras em sistemas orgânicos de produção.

Seguindo as normas que determinam a agricultura orgânica, onde fica proibido o uso de produtos químicos, materiais sintéticos, organismos geneticamente modificados e radiações ionizantes. Entretanto que se utilize de métodos culturais, mecânicos e biológicos para o controle de pragas, visando uma sustentabilidade econômica e ecológica com objetivo de proteção do meio ambiente e de seus recursos (Decreto $\mathrm{N}^{\circ} 6.323$ de 27 de dezembro de 2007).

\section{Controle Mecânico e Cultural}

O controle mecânico é uma das alternativas para o controle de formigas cortadeiras, que consiste na extirpação dos formigueiros em determinada área, com o auxílio de enxadas e enxadões (OLIVEIRA et al., 2011).

Entretanto, essa técnica é viável apenas para formigueiros novos (até 4 meses de idade, onde consegue atingir até $20 \mathrm{~cm}$ de profundidade, onde se encontra a rainha), a partir dessa profundidade as colônias abrem outras panelas mais profundas, dificultando esse controle (OLIVEIRA et al., 2011).

Contudo, fazendo parte do conhecimento popular, essa técnica de controle é pouco utilizada (MORESSI et al., 2007).

Além disso, uma das técnicas utilizadas é o controle físico, que são o uso de barreiras físicas para proteger a parte aérea da planta, principalmente as mudas (ARAÚJO et al., 2003; OLIVEIRA et al., 2011).

Estudos comprovam a utilização de barreiras físicas sendo utilizados, cones de cilindro de garrafas pet; coroamento com palha ao redor das mudas, dificultando o acesso das formigas (MORESSI et al., 2007); cones confeccionados com lâmina de acetato, sendo capaz de impedir o acesso a fonte de alimento das formigas (ALMEIDA et al., 2013).

\section{Controle Biológico}

Para que exista um sucesso no manejo de formigas cortadeiras, por se tratar de insetos onde a biologia e o comportamento são complexos, é preciso um conhecimento amplo de suas interações com o ambiente (OLIVEIRA et al., 2011).

O sub-bosque entre inúmeras vantagens que podem trazer ao ambiente, desempenha importantes papeis como corredores de fauna entre áreas florestais (ZANETTI et al., 1999), oferecendo abrigo e alimentos para inimigos naturais como as aves insetívoras que auxiliam no controle biológico (ALMEIDA e ALVES, 1982; OLIVEIRA et al, 2011).

Bem como, obtendo outras opções de substratos vegetais para o fungo das formigas, principalmente se forem atrativas para elas (DELLA LUCIA et al., 2014).

Segundo Lima (2019) a manutenção do sub-bosque na cultura do eucalipto pode ser considerada uma medida auxiliar no controle de formigas cortadeiras, onde a densidade do subbosque influencia na infestação dessa praga, e quanto mais denso for o sub-bosque, menor será o número de formigueiros.

Um exemplo disso, Almeida et al., (1983) demostrou a importância do sub-bosque como ferramenta auxiliar no controle das formigas cortadeiras, como a diminuição de formigueiros em sub-bosque denso comparado a áreas sem sub-bosque. 
Desse modo, ambientes agrícolas diversificados podem ser efetivos contra a herbívora, pois uma diversidade vegetal com outras plantas companheiras, impõe barreiras físicas e/ou químicas, podendo dificultar a localização, reprodução e a colonização da cultura hospedeira pelas pragas (BARBOSA et al., 2011).

Além das aves, outros animais são considerados inimigos naturais das formigas cortadeiras, como: sapos, rãs, galinhas, gaviões, cobras, lagartos, tamanduás, tatus (WILCKEN; BERTI FILHO, 1994), e uma grande quantidade de invertebrados (Tabela 2).

Por exemplo, diversos outros organismos podem ser encontrados nos ninhos das formigas cortadeiras, alguns até mesmo convivendo juntamente com elas nos jardins de fungos (DELLA LÙCIA, 1993; WILCKEN; BERTI FILHO, 1994).

Tabela 2. Invertebrados inimigos naturais das formigas cortadeiras (ARAÚJO et al., 2011) adaptada.

\begin{tabular}{|c|c|}
\hline Organismo & Formiga \\
\hline 1. Ácaros & Atta spp. \\
\hline \multirow[t]{2}{*}{ 2. Aranhas } & Atta spp. \\
\hline & Acromymerx spp. \\
\hline \multicolumn{2}{|l|}{ 3. Besouros } \\
\hline Canthon virens (Scarabaeidae) & Atta spp. \\
\hline Canthon dives (Scarabaeidae) & Atta spp. \\
\hline Taeniolobus sulcipes (Carabidae) & Atta spp. \\
\hline \multicolumn{2}{|l|}{ 4. Hemiptera } \\
\hline Vescia angrensis (Reduviidae) & Atta spp. \\
\hline \multicolumn{2}{|l|}{ 5. Hymenoptera (Formicidae) } \\
\hline Eciton hamatum & Acromymerx spp. \\
\hline Nomamyrmex esenbecki & Atta spp. \\
\hline Nomamyrmex hartigi & Atta spp. \\
\hline Nylanderia fulva & Atta spp. \\
\hline Pseudoatta argentina & Acromymerx lundi \\
\hline \multirow[t]{3}{*}{ Solenopsis spp. } & Atta spp. \\
\hline & Acromymerx spp. \\
\hline & Acromymerx spp. \\
\hline \multirow[t]{2}{*}{ Acromyrmex ameliae } & Acromymerx subterraneus subterraneus \\
\hline & Acromymerx subterraneus brunneus \\
\hline \multicolumn{2}{|l|}{ 6. Moscas } \\
\hline \multirow[t]{2}{*}{66 espécies de forídeos } & Atta spp. \\
\hline & Acromymerx spp. \\
\hline 7. Nematoides & Acromymerx octospinosus \\
\hline \multicolumn{2}{|l|}{ 8. Fungos } \\
\hline \multirow[t]{2}{*}{ Enorme variedade de fungos e leveduras } & Atta spp. \\
\hline & Acromymerx spp. \\
\hline
\end{tabular}




\section{Revista Ambientale \\ Revista da Universidade Estadual de Alagoas/UNEAL e-ISSN 2318-454X, Ano 13, Vol. 13 (4), 2021 \\ https://doi.org/10.48180/ambientale.v13i4.318}

Alguns fungos entomopatogênicos como as espécies Metarhizium anisopliae (Metsch.) e Beauveria bassiana (Bals.) que são generalistas, são capazes de infectar uma grande variedade de insetos, levando os seus hospedeiros à morte (AUGUSTIN et al., 2011).

Segundo Travaglini et al. (2020), utilizando o fungo B. bassiana, foram eficientes na germinação e penetração em operárias de Atta sexdens, principalmente nos tegumentos das larvas imaturas, permitindo melhor adesão e germinação do fungo, interferindo diretamente na geração de novos indivíduos e dessa forma afetando toda a colônia.

Um exemplo disso, em condições de laboratório 4 isolados de $M$. anisopliae e 4 isolados de B. bassiana foram patogênicos para espécies de Atta bisphaerica e Atta sexdens rubropilosa causando mais de 50\% de morte 72 horas após a inoculação (CASTILHO et al., 2010).

Para o controle de espécies de Atta cefalotes, 23 extratos bacterianos exibiram algum tipo de atividade para controlar essa espécie de formiga, alguns por contato, ingestão ou antifúngicas, demonstrando um potencial a ser explorado para o controle biológico de insetos (REYES et al., 2019).

Portanto, segundo Aguiar-Menezes (2003) o controle biológico busca a redução do nível populacional de determinada espécie considerada como praga, mantendo-a abaixo do nível em que é capaz para que não cause prejuízos econômicos.

\section{Iscas Biológicas e plantas repelentes}

Os inseticidas botânicos podem derivar de toda parte da planta ou de partes dela, sendo considerado metabólicos secundário (KIM et al., 2003), através dos seus princípios ativos que são obtidos do material vegetal, que pode ser moídos sendo transformados em pó, farinha, ou através da extração aquosa ou mesmo com solventes orgânicos (AGUIAR-MENEZES, 2005).

A saber, diversos trabalhos evidenciam a eficiência de espécies vegetais no controle de formigas cortadeiras ou do fungo simbionte sendo: Aristolochia trilobata (Aristolochiaceae) (OLIVEIRA et al., 2017); Ateleia glazioviana (Fabaceae) (CANTARELLI et al., 2005); Canavalia ensiformis (Fabaceae) (HEBLING et al., 2000a); Cipadessa fruticosa (Meliaceae) (LEITE et al., 2005); Eplingiella fruticosa (Lamiaceae) (SILVA, 2017) Eugenia florida e Eugenia handroana (Myrtaceae) (TORRES et al, 2014); Ipomoea batatas (Convolvulaceae) (HEBLING et al., 2000b); Ricinus communis (Euphorbiaceae) (ACÁCIO-BIGI et al., 2004); Simarouba versicolor (Simaroubaceae) (PEÑAFLOR et al., 2009); Sesamum indicum (Pedaliaceae) (RIBEIRO et al, 1998; BUENO et al., 2004; MORINI et al., 2005), Trichilia pallida (Meliaceae) e Zanthoxylum pohlianum (Rutaceae) (TORRES et al, 2014); Melaleuca alternifólia (Myrtaceae) (BUTELERA et al., 2019); Simarouba amara (Simaroubaceae) e Zanthoxylum rhoifolium (Rutaceae) (GOMES, 2016); Sesamum indicum (Pedaliaceae) (RIBEIRO et al., 1998; BUENO et al., 2004; MORINI et al., 2005; ARAÚJO, 2016).

Através dos princípios agroecológicos, que contemple o uso responsável dos recursos naturais, como a água e o solo, principalmente nos sistemas orgânicos de produção as iscas biológicas, são eficaz alternativa de controle para as formigas cortadeiras (NASCIMENTO et al, 2018).

Nesse sentido, outra alternativa são os óleos essenciais de plantas aromáticas que possuem efeitos inseticidas (ISMAN, 2000), como o óleo de eucalipto citriodora (Eucalyptus citriodora) e da citronela presente no capim-limão (Cymbopogon citratus) (AGUIAR-MENEZES, 2005).

Um exemplo disso, é que segundo Lazzari et al. (2019) o óleo da casca da laranja, mostrou um potencial para controle de formigas cortadeiras. O óleo de E. fruticosa também se mostrou 
como alternativa promissora como controle de formigas cortadeiras do gênero Acromyrmex, causando repelência e afetando o comportamento de caminhamento dessas formigas (SILVA, 2007).

Óleos também foram testados com efeitos positivos para a fumaginação como o extraído da Aristolochia trilobata causando forte repelência e irritabilidade nos formigueiros de Acromyrmex balzani e Atta sededens, mostrando uma rápida e eficiente ação inseticida, podendo ser utilizado para formulação de novos inseticidas (OLIVEIRA et al., 2017).

A saber, outro exemplo é o óleo de Melaleuca alternifólia, com resultados como um forte repelente de formigas cortadeiras a curto prazo ou como proteção de plantas através desse óleo, podendo ser utilizado em sistemas orgânicos de produção (BUTELER et al., 2019).

Portanto, no Brasil apesar de estar sendo estudado o controle de substâncias naturais para o controle de formigas cortadeiras, ainda são poucos os resultados práticos e existindo a necessidade de produtos com a utilização comercial.

\section{Conclusão}

O objetivo do presente estudo foi buscar alternativas para o manejo de controle para formigas cortadeiras em sistemas orgânicos de produção.

Através dos métodos já conhecidos na agricultura orgânica como rotação de culturas, consórcios entre linhas de cultivos e manutenção do sub-bosque, servindo como abrigo para inimigos naturais e pássaros. Pois quanto mais limpa a área melhor servira para a formação de formigueiros.

Portanto, os métodos apresentados nesse estudo, controle mecânico, biológico, iscas biológicas e plantas atraentes, se mostraram eficientes no controle de formigas cortadeiras em sistemas orgânicos de produção.

Entretanto, é preciso que sempre realize o monitoramento prévios nos cultivos orgânicos para que não se estabeleça de maneira incontrolável essa praga.

Contudo, para o controle de formigas cortadeiras na agricultura orgânica é preciso que se utilize diversos métodos em conjunto, não utilizando apenas um e que haja uma sinergia entre eles. Que sejam de baixo custo e fácil implementação e condução, para que estejam disponíveis principalmente para pequenos produtores orgânicos.

Existem alternativas para o controle de formigas cortadeiras em sistemas orgânicos, mas é preciso a realização de mais estudos e a disponibilidade desses produtos no mercado.

\section{Conflitos de interesse}

Os autores desse manuscrito não declararam conflito de interesses.

\section{Referências}

ACÁCIO-BIGI, M. F. M. et al. Activity of the Ricinus communis (Euphorbiaceae) and ricinine to the leaf-cutting ants Atta sexdens rubropilosa Forel, 1908, (Hymenoptera, Formicidae) and 
Revista Ambientale

Revista da Universidade Estadual de Alagoas/UNEAL e-ISSN 2318-454X, Ano 13, Vol. 13 (4), 2021

https://doi.org/10.48180/ambientale.v13i4.318

to the symbiotic fungus Leucoagaricus gongylophorus (Singer) Möller. Pest Manager Science, v. 60, p. 933-938, 2004.

AGUIAR MENEZES, E. de L. Controle biológico de pragas: princípios e estratégias de aplicação em ecossistemas agrícolas. Embrapa Agrobiologia (Documentos, 164), 44 p. 2003. AGUIAR-MENEZES, E. de L. Inseticidas botânicos: seus princípios ativos, modo de ação e uso agrícola. Embrapa Agrobiologia (Documentos, 205) 58 p. 2005.

ALMEIDA, A.F. de et al. A avifauna e o sub-bosque como fatores auxiliares no controle biológico das saúvas em florestas implantadas. Silvicultura, v. 8, n. 28, p. 145-150, 1983.

ALMEIDA, AF de; ALVES, J. E. M. Controle integrado de saúvas na Aracruz Florestal [Brasil]. 1982.

ALMEIDA, J. T. S.; MEDICI, L. O.; AGUIAR-MENEZES, E. de L. Eficiência e princípio de funcionamento de barreira física cônica contra as quenquéns. Floresta, v. 43, n. 4, p. 633-642, 2013.

ARAÚJO, M. S. et al. Predadores e outros organismos associados aos ninhos de formigascortadeiras. In: DELLA LUCIA, T.M.C. Formigas-cortadeiras: da biologia ao manejo. Viçosa-MG: UFV, p. 311-320, 2011.

ARAÚJO, M. S.; DELLA LUCIA, T. M. C.; SOUZA, D. J. Estratégias alternativas de controle de formigas-cortadeiras. Bahia Agrícola, Salvador, v. 6, p. 71 - 74, 2003.

AUGUSTIN, J. O. et al. Fungos parasitas de formigas-cortadeiras e de seu fungo mutualıstico. In: DELLA LUCIA, T.M.C. Formigas cortadeiras: da bioecologia ao manejo. Viçosa- MG: UFV, p. 284-311, 2011.

BACCARO, F. B. et al. Guia para os gêneros das formigas do Brasil. Manaus: Inpa. 388 p., 2015.

BARBOSA, F. S. et al. Potencial das flores na otimização do controle biológico de pragas para uma agricultura sustentável. Revista Brasileira de Agroecologia, v. 6, n. 2, p. 101-110, 2011. BRASIL. Decreto $\mathbf{N}^{\mathbf{0}}$ 6.323, de 27 de dezembro de 2007. Dispõe sobre a agricultura orgânicas e dá outras providências. 2007.

BUENO, O. C. et al. Activity of sesame leaf extracts to the leaf-cutting ant Atta sexdens rubropilosa (Hymenoptera: Formicidae). Sociobiology, p. 511-518, 2004.

BUTELER, M. et al. Novel organic repellent for leaf-cutting ants: tea tree oil and its potential use as a management tool. International Journal of Pest Management, p. 1-9, 2019.

CANTARELLI, E. B. et al. Silvicultura de precisão no monitoramento e controle de formigas cortadeiras em plantios de pinus. 2005. Tese de Doutorado. Universidade Federal de Santa Maria. 2005.

CASTILHO, A. M. C. et al. Seleção de isolados de Metarhizium anisopliae e Beauveria bassiana patogênicos a soldados de Atta bisphaerica e Atta sexdens rubropilosa em condições de laboratório. Ciência Rural, v. 40, n. 6, p. 1243-1249, 2010.

CORASSA, J. de N. et al. Biodiversidade da mirmecofauna em diferentes usos do solo no Norte Mato-Grossense. Comunicata Scientiae, v. 6, n. 2, p. 154-163, 2015.

DAGATTI, C. V. et al. Actividad forrajera de Acromyrmex striatus (Roger, 1863) (Formicidae: Attini) en un viñedo orgánico en Mendoza, Argentina. Ediciones INTA, 2019. DELlA LUCIA, T. M. C.; ARAÚJO, M. S. Formigas cortadeiras: Atualidades no combate. Manejo Integrado-Doenças, Pragas e Plantas Daninhas; Zanbolim, L., Ed, p. 245-273, 2000.

DELLA LUCIA, T. M.C; GANDRA, L. C.; GUEDES, R. N.C. Managing leaf-cutting ants: peculiarities, trends and challenges. Pest management science, v. 70, n. 1, p. 14-23, 2014. 
Revista Ambientale

Revista da Universidade Estadual de Alagoas/UNEAL e-ISSN 2318-454X, Ano 13, Vol. 13 (4), 2021

https://doi.org/10.48180/ambientale.v13i4.318

ESTRADA, M. A. et al. Diversidade, riqueza e abundância da mirmecofauna em áreas sob cultivo orgânico e convencional. Acta Biológica Catarinense, v.6, n.2, p.87-103, 2019.

GIESEL, A. et al. Ocorrência de formigas cortadeiras em campos de altitude no sul do Brasil. Research, Society and Development, v. 9, n. 8, 2020.

GOMES, M. de C. A. R. et al. Toxicity of plant extracts from Bahia, Brazil, to Atta sexdens sexdens workers (Hymenoptera: Formicidae). Sociobiology, v. 63, n. 2, p. 770-776, 2016.

HEBLING, M. J. A. et al. Toxic effects of Canavalia ensiformis L.(Leguminosae) on laboratory colonies of Atta sexdens L.(Hym., Formicidae). Journal of Applied Entomology, v. 124, n. 1, p. 33-35, 2000 a.

HEBLING, M. J. A. et al. Effects of leaves of Ipomoea batatas (Convolvulaceae) on nest development and on respiratory metabolism of leaf-cutting ants Atta sexdens L.(Hym., Formicidae). Journal of Applied Entomology, v. 124, n. 5-6, p. 249-252, 2000 b.

HÖLLDOBLER, B.; WILSON E.O. The ants. Cambridge: Harvard University Press; 746 p. 1990.

ISMAN, M. B. Plant essential oils for pest and disease management. Crop protection, v. 19, n. 8-10, p. 603-608, 2000.

KIM, S.L. et al. Insecticidal activities of aromatic plant extracts and essential oils against Sitophilus oryzae and Callosobruchus chinensis. Journal of Stored products research, v. 39, n. 3, p. 293-303, 2003.

LAZZARI, E. et al. Natural Biocide for Combating Lest Cutting Ants. Brazilian Journal of Technology, v. 2, n. 1, p. 513-522, 2019.

LEITE,

A. C. et al. Limonoids from Cipadessa fruticosa and Cedrela fissilis and their insecticidal activity. Journal of the Brazilian Chemical Society, v. 16, n. 6B, p. 1391-1395, 2005.

LEMES, P. G.; ZANUNCIO J. C. Novidades no controle de formigas. Revista campo e negócio. 2019. Disponível em < Novidades no controle de formigas - Revista Campo \& Negócios (revistacampoenegocios.com.br) > Acesso em 02 Jan. 2021.

MARCHIORI, J.J.P. Mirmecofauna e suas interações com hemípteros fitófagos em áreas cultivadas. Dissertação (Mestrado em Fitossanidade e Biotecnologia Aplicada) - Universidade Federal Rural do Rio de Janeiro, 2020.

MARINHO, C. G. S.; DELLA LUCIA, T. M.C.; PICANÇO, M. C. Fatores que dificultam o controle das formigas cortadeiras. Bahia Agrícola, v. 7, n. 2, p. 18-21, 2006.

MORESSI, M. et al. Resumo expandido 060. A eficiência do controle mecânico de formigas cortadeiras (Atta laevigata) no reflorestamento com espécies nativas. Biológico, São Paulo, v. 69, n. suplemento 2, p. 471-473, 2007.

NADAI, J. et al. Efeito de iscas formicidas granuladas sobre a biodiversidade de mirmecofauna não alvo em serapilheira de eucalipto no Estado do Mato Grosso. Comunicata Scientiae. v.4, n.1: 35-42.2012.

NASCIMENTO, A. S. do. et al. Controle de formigas cortadeiras na produção orgânica de frutas, com utilização de isca biológica. Embrapa Mandioca e Fruticultura-Comunicado Técnico (INFOTECA-E), 2018.

OLIVEIRA, B. M. S. et al. Essential oil of Aristolochia trilobata: synthesis, routes of exposure, acute toxicity, binary mixtures and behavioral effects on leaf-cutting ants. Molecules, v. 22, n. 3, p. 335, 2017.

OLIVEIRA, C. M. et al. Crop losses and the economic impact of insect pests on Brazilian agriculture. Crop Protection, v. 56, p. 50-54, 2014. 
Revista Ambientale

Revista da Universidade Estadual de Alagoas/UNEAL e-ISSN 2318-454X, Ano 13, Vol. 13 (4), 2021

https://doi.org/10.48180/ambientale.v13i4.318

OLIVEIRA, M. A. et al. Manejo de formigas-cortadeiras. In: DELLA LUCIA T. M. C. Formigas-cortadeiras: da biologia ao manejo. Viçosa-MG: UFV. p. 400-419. 2011.

PEÑAFLOR, M. F. G.V. et al. Toxicidade de Substâncias Isoladas de Simarouba versicolor St. Hil.(Simaroubaceae) para Formigas Cortadeiras Atta sexdens L.(Hymenoptera: Formicidae) e para o seu Fungo Simbionte Leucoagaricus gongylophorus (Singer) Möller. BioAssay, v. 4, 2009.

PERRI, D. et al. Plant-based compounds with potential as push-pull stimuli to manage behavior of leaf-cutting ants. Entomologia Experimentalis et Applicata, v. 163, n. 2, p. 150-159, 2017. REYES, A. O. et al. Bacterial extracts for the control of Atta cephalotes (Hymenoptera: Formicidae) and its symbiotic fungus Leucoagaricus gongylophorus (Agaricales: Agaricaceae). Revista de Biología Tropical, v. 67, n. 4, 2019.

RIBEIRO, S B. et al. Activity of sesame leaf extracts against the symbiotic fungus of Atta sexdens L. Anais da Sociedade Entomológica do Brasil, v. 27, n. 3, p. 421-426, 1998.

SANTOS LIMA, T. L. Infestações de formigas cortadeiras (Hymenoptera: Formicidae) em plantio de eucalipto com diferentes densidades de sub-bosque na região de Campos Gerais no Estado do Paraná. 2019. Monografia (Graduação em Engenharia Florestal) Instituto de Floresta, Universidade Federal Rural do Rio de Janeiro. Seropédica, 2019.

SILVA, D. C. Diversidade química, genética e estudo do potencial formicida de óleos essenciais de Eplingiella fruticosa (Salzm. Ex Benth) Harley \& J.F.B. Pastore. 2017. Tese (doutorado em Agricultura e Biodiversidade) - Universidade Federal de Sergipe. São Cristovão, 2017.

SILVEIRA, M.V. de S. et al. Práticas agroecológicas: controle alternativo aplicado a formigas cortadeiras no Assentamento 24 de Abril, em Acarape-CE. Cadernos de Agroecologia, v. 15, n. 2, 2020.

TATAGIBA-ARAUJO, G. D. de F. Uso de extratos feromonais e de farinha de gergelim em iscas destinadas ao controle de formigas-cortadeiras Tese (Doutorado em Produção Vegetal). Universidade Estadual do Norte Fluminense Darcy Ribeiro. Campos dos Goytacazes, 2017.

TORRES, A. de F. et al. Atividade inseticida de extratos de plantas no controle de formiga cortadeira, em cafeeiro. 2013.

TRAVAGLINI, R. V. et al. Description using ultramorphological techniques of the infection of Beauveria bassiana (Bals.-Criv.) Vuill. in larvae and adults of Atta sexdens (Linnaeus, 1758) (Hymenoptera: Formicidae). Boletim do Museu Paraense Emílio Goeldi-Ciências Naturais, v. 15, n. 1, p. 101-111, 2020.

WARD, P. Taxonomy, phylogenetics, and evolution. In: LACH, L.; PARR, C. L.; ABBOTT, K. L. (Eds). Ant Ecology. New York: Oxford University Press 402 p. 2010.

WILCKEN, C. F.; BERTI FILHO, E. Controle biológico de formigas cortadeiras. PCMIP/IPEF, p. 1-5, 1994.

ZANETTI, R. et al. Efeito da espécie de Eucalipto e da vegetação nativa circundante sobre o custo de combate a sauveiros em Eucaliptais. Revista Árvore, Viçosa, v. 23, n. 3, p. 321-325, 1999. 